\title{
Hypereosinophilic syndromes: A multicenter, retrospective analysis of clinical characteristics and response to therapy
}

\section{Citation}

Ogbogu, Princess U., Bruce S. Bochner, Joseph H. Butterfield, Gerald J. Gleich, Johannes HussMarp, Jean Emmanuel Kahn, Kristin M. Leiferman, et al. 2009. Hypereosinophilic syndromes: A multicenter, retrospective analysis of clinical characteristics and response to therapy. Journal of Allergy and Clinical Immunology 124, no. 6: 1319-1325.e3. doi:10.1016/j.jaci.2009.09.022.

\section{Published Version}

doi:10.1016/j.jaci.2009.09.022

\section{Permanent link}

http://nrs.harvard.edu/urn-3:HUL.InstRepos:27377612

\section{Terms of Use}

This article was downloaded from Harvard University's DASH repository, and is made available under the terms and conditions applicable to Other Posted Material, as set forth at http:// nrs.harvard.edu/urn-3:HUL.InstRepos:dash.current.terms-of-use\#LAA

\section{Share Your Story}

The Harvard community has made this article openly available.

Please share how this access benefits you. Submit a story.

Accessibility 


\title{
Hypereosinophilic syndromes: a multicenter, retrospective analysis of clinical characteristics and response to therapy
}

\author{
Princess U. Ogbogu, M.D. ${ }^{1}$, Bruce S. Bochner, M.D. ${ }^{2}$, Joseph H. Butterfield, M.D. ${ }^{3}$, Gerald J.

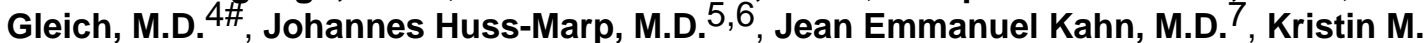 \\ Leiferman, M.D. ${ }^{*}$, Thomas B. Nutman, M.D. ${ }^{1}$, Florian Pfab, M.D. 5,6 , Johannes Ring, M.D. 6 \\ Marc E. Rothenberg, M.D., Ph.D. ${ }^{8}$, Florence Roufosse, M.D. ${ }^{9}$, Marie-Helene Sajous, M.D. ${ }^{2}$, \\ Javed Sheikh, M.D. ${ }^{10}$, Dagmar Simon, M.D. ${ }^{11}$, Hans-Uwe Simon, M.D., Ph.D. ${ }^{12}$, Miguel L. \\ Stein, M.D. ${ }^{8}$, Andrew Wardlaw, M.D. ${ }^{13}$, Peter F. Weller, M.D. ${ }^{10}$, and Amy D. Klion, M.D. ${ }^{1}$
}

${ }^{1}$ National Institute of Allergy and Infectious Diseases, Laboratory of Parasitic Diseases, National Institutes of Health, Bethesda, Maryland ${ }^{2}$ Division of Allergy and Clinical Immunology, Department of Medicine, Johns Hopkins University School of Medicine, Baltimore, Maryland ${ }^{3}$ Division of Allergic Diseases, Mayo Clinic, Rochester, MN ${ }^{4}$ Departments of Dermatology * and Medicine \#, University of Utah, Salt Lake City, Utah ${ }^{5}$ ZAUM - Center for Allergy and Environment, Division of Environmental Dermatology and Allergy, Helmholtz Center Munich / Technische Universität München, Munich, Germany ${ }^{6}$ Department of Dermatology and Allergy Biederstein, Technische Universität München, Munich, Germany ${ }^{7}$ Department of Internal Medicine, Hôpital, Foch, Suresnes, France. French Eosinophil Network, Department of Immunology, CHRU de Lille, Lille, France ${ }^{8}$ Division of Allergy and Immunology, Cincinnati Children's Hospital Medical Center, Cincinnati, Ohio ${ }^{9}$ Département de Médecine Interne, Hôpital, Erasme, Université Libre de Bruxelles, Brussels, Belgium; Institute for Medical Immunology, Université Libre de Bruxelles, Gosselies, Belgium ${ }^{10}$ Beth Israel Deaconess Medical Center, Harvard Medical School, Boston, Massachusetts ${ }^{11}$ Department of Dermatology, Inselspital, University of Bern, Bern, Switzerland ${ }^{12}$ Institute of Pharmacology, University of Bern, Bern, Switzerland ${ }^{13}$ Institute for Lung Health, University of Leicester, United Kingdom.

\section{Abstract \\ Background-Hypereosinophilic syndromes (HES) are a heterogeneous group of rare disorders defined by persistent blood eosinophilia $\geq 1.5 \times 10^{9} / \mathrm{L}$, absence of a secondary cause, and evidence of eosinophil-associated pathology. With the exception of a recent multicenter trial of mepolizumab}

\footnotetext{
(C) 2009 American Academy of Allergy, Asthma and Immunology. Published by Mosby, Inc. All rights reserved.

Corresponding author. Amy D. Klion, M.D., Bldg 50, Rm 6351, Laboratory of Parasitic Diseases, NIAID, National Institutes of Health, Bethesda, MD 20892, (301) 435-8903 (tel), (301) 451-2029 (FAX), aklion@nih.gov.

Publisher's Disclaimer: This is a PDF file of an unedited manuscript that has been accepted for publication. As a service to our customers we are providing this early version of the manuscript. The manuscript will undergo copyediting, typesetting, and review of the resulting proof before it is published in its final citable form. Please note that during the production process errors may be discovered which could affect the content, and all legal disclaimers that apply to the journal pertain.

Author Contributions.

P.O. collected and analyzed the data and wrote the paper; B.S.B,, J.H.B., G.J.G., J.H., J.E.K., J.R., M.E.R., F.R., H.U.S., A.W., and P.F.W helped design the research, collect and analyze the data and edit the paper, J.H.B. helped design the research, collect and analyze the data and edit the paper, K.M.L., F.P., M.S., J.S., D.S., and M.L.S. helped collect and analyze the data and edit the paper, T.B.N. helped design the research, analyze the data and edit the paper, and A.D.K. helped design the study, collect and analyze the data and write the paper.

Financial disclosures: Dr. Sheikh has served as a consultant, speaker's bureau and received research support from GlaxoSmithKline and has been on speaker's bureau for Novartis. Drs. Weller and Kahn have served as consultants to GlaxoSmithKline. Drs. Wardlaw and Kahn have received funding for research from and have served on the advisory board of GlaxoSmithKline.
} 
(anti-IL-5 monoclonal antibody), published therapeutic experience has been restricted to case reports and small case series.

Objective - The purpose of the study was to collect and summarize baseline demographic, clinical and laboratory characteristics in a large, diverse cohort of patients with HES and to review responses to treatment with conventional and novel therapies.

Methods-Clinical and laboratory data from 188 patients with HES, seen between January 2001 and December 2006 at eleven institutions in the United States and Europe, were collected retrospectively by chart review.

Results-Eighteen of 161 patients (11\%) tested were FIP1L1-PDGFRA mutation-positive and $29 / 168$ patients tested $(17 \%)$ had a demonstrable aberrant or clonal $\mathrm{T}$ cell population. Corticosteroid monotherapy induced complete or partial responses at 1 month in 85\% (120/141) of patients with most remaining on maintenance doses (median $10 \mathrm{mg}$ prednisone equivalent daily for 2 months-20 years). Hydroxyurea and interferon-alpha (used in 64 and 46 patients, respectively) were also effective, but their use was limited by toxicity. Imatinib (used in 68 patients) was more effective in patients with the FIPIL1-PDGFRA mutation (88\%) than in those without (23\%; p<0.001).

Conclusion-This study, the largest clinical analysis of patients with HES to date, not only provides useful information for clinicians but should stimulate prospective trials to optimize treatment of HES.

\section{Keywords}

eosinophil; hypereosinophilic syndrome; FIP1L1-PDGFRA

\section{Introduction}

The hypereosinophilic syndromes (HES) are a diverse group of rare disorders defined by the presence of persistent peripheral blood eosinophilia $\geq 1.5 \times 10^{9} / \mathrm{L}$, the absence of a secondary cause of eosinophilia, and evidence of eosinophil-associated end organ damage1. The clinical heterogeneity of HES has long been recognized 2; however, it is only recently that the techniques have become available to identify subtypes of HES with different underlying etiologies. The two best described of these subtypes are lymphocytic variant HES (L-HES) ${ }^{3}$, in which the underlying cause of the eosinophilia is secretion of eosinophilopoietic cytokines by T lymphocytes, and myeloproliferative HES/chronic eosinophilic leukemia (CEL) 4, 5, most commonly due to an interstitial deletion in chromosome 4 . These subtypes are associated with dramatic differences in clinical presentation, prognosis and responses to therapy 6 . The availability of new targeted therapies, including tyrosine kinase inhibitors and humanized monoclonal antibodies, have only increased the importance of developing a better understanding of the etiologies and pathogenesis of HES, as these may be predictors of treatment response.

Despite the fact that a wide variety of agents have been used for the treatment of HES, published therapeutic experience has been largely restricted to case reports and small case series, the exception being a recently published multicenter trial of the monoclonal anti-IL-5 antibody, mepolizumab, as a steroid-sparing agent in HES ${ }^{7}$. The lack of published data is due, in large part, to the paucity of affected patients as well as to the heterogeneity of presenting symptoms. This retrospective, multicenter analysis sought to collect and summarize the baseline demographic, clinical and laboratory characteristics in a large, diverse cohort of patients with HES and to review responses to treatment with both conventional and novel therapies. 


\section{Methods}

Patients meeting diagnostic criteria for HES $^{6}$, evaluated between January 2001 and December 2006, at eleven participating institutions with expertise in the evaluation of eosinophilic disorders, were included in the study. Inclusion criteria were: documentation of a peripheral eosinophil count of $\geq 1.5 \times 10^{9} / \mathrm{L}$ and signs or symptoms of end organ involvement for which another etiology could not be found. Patients with neoplasms (other than FIPIL1/PDGFRA (FP)-positive CEL), biopsy-positive Churg-Strauss vasculitis, single organ eosinophilic diseases without blood eosinophilia, and overlap syndromes ${ }^{6}$ were excluded from the study. Patients were enrolled consecutively at each site beginning with patients seen at initial or follow-up visit in December 2006 and proceeding backwards in time until 50 patients were included from a given site or the year 2001 was reached.

Clinical and laboratory data pertaining to baseline characteristics and treatment responses were collected following chart review, entered without identifiers into a database and compiled for analysis (see Online Repository). Potential duplicates were removed on the basis of a combination of factors, including birth year, gender, and clinical features. IRB approval and informed consent were obtained as required by each institution.

All 188 patients underwent detailed evaluation at the contributing clinical sites, including a complete history, physical exam, and laboratory evaluation (Table 1). Parameters previously shown or suspected to have prognostic significance in HES, e.g. peak eosinophil count, serum IL-5, total IgE, vitamin B12, tryptase, and TARC (thymus and activation-related chemokine (CCL17)) levels, were assessed. Results of FP mutation analysis (by nested polymerase chain reaction (PCR) or fluorescence in situ hybridization FISH)) and assessment of T cell clonality and phenotype by peripheral blood flow-cytometry and/or T cell receptor rearrangement PCR (TCR) were also included in the analysis. Although whole blood flow cytometry techniques and antibody panels varied among the sites, CD3, CD4 and CD8 antibodies, which detect the most common aberrant phenotypes in L-HES $\left(\mathrm{CD}^{-} \mathrm{CD}^{+}{ }^{+} \text {and } \mathrm{CD} 3^{+} \mathrm{CD} 4^{-} \mathrm{CD} 8^{-}\right)^{8}$, were included in all panels. Serum TARC levels were determined using commercially available ELISA kits from R\&D Systems Europe (BRU, GER, LEIC; detection limit $7 \mathrm{pg} / \mathrm{ml}$ ) or by ELISA from Thermo Fisher Scientific (BETH; detection limit 0.8 pg/ml). Serum IL-5 levels were determined using commercially available ELISA kits from BD Biosciences Pharmingen or R\&D Systems (CIN, BRU, LEIC, SUR, MINN, BOS, SLC; detection limit $7.8 \mathrm{pg} / \mathrm{ml}$ ) or by ELISA by Thermo Fisher Scientific (BETH; detection limit $0.8 \mathrm{pg} / \mathrm{ml}$ ). Laboratory information, including results of FP mutation testing, T cell studies and serum TARC levels, was requested on all patients; however, due to the retrospective nature of the study, all results were not available in all cases. Normal values were defined as follows: $\mathrm{IgE}<100 \mathrm{IU} / \mathrm{ml}$, serum IL-5 $<14.1 \mathrm{pg} / \mathrm{ml}$, tryptase $<11.5 \mathrm{ng} / \mathrm{ml}$, vitamin B12 $<950 \mathrm{pg} / \mathrm{ml}$, and TARC $<500 \mathrm{pg} / \mathrm{ml}$.

Clinical responses at 1 month of treatment (full, partial or no response) were recorded, as well as the maintenance dose, the maximal dose (for prednisone only), and whether each drug was given as monotherapy. Complete responses were defined as decrease of the eosinophil count to the normal range $\left(0-0.5 \times 10^{9} / \mathrm{L}\right)$ and symptomatic improvement after one month of treatment. Partial responses were defined as decrease of the eosinophil count, but not to the normal range, and/or symptomatic improvement after one month of treatment. No response was defined as a stable or increasing eosinophil count and no symptomatic improvement after one month of treatment.

\section{Statistical Analysis}

Nonparametric comparisons of group means were made using the Mann-Whitney U test. Proportions were compared using Fisher exact test. A p-value of less than 0.05 was considered significant for all tests. 


\section{Results}

\section{Baseline characteristics}

Of the 188 patients evaluated, 104 were male (55\%) and 84 were female (45\%). The median age at diagnosis was 45 years of age (range 6-85 years). The peak recorded absolute eosinophil counts ranged from $1.5-400 \times 10^{9} / \mathrm{L}$ with a geometric mean $(\mathrm{GM})$ peak eosinophil count of $6.6 \times 10^{9} / \mathrm{L}$ (Table 1 ). Of the 161 patients tested for the FP mutation, $18(11 \%)$, all of whom were male, were positive. Of the 168 patients who were evaluated for clonal or aberrant populations of T cells, 29 (17\%; 15 male and 14 female) were positive by PCR ( $n=14)$, flow cytometry $(n=3)$, or both $(n=12)$. These patients were classified as lymphocytic variant HES (L-HES). There were 4 patient deaths reported during the study period, 2 of which were thought to be secondary to HES (due to eosinophilic heart disease).

Serum tryptase levels were reported for 123 patients (66\%) and ranged from $1-131 \mathrm{ng} / \mathrm{ml}(\mathrm{GM}$ $7.6 \mathrm{ng} / \mathrm{ml}$ ). Elevated serum tryptase levels were significantly more common in patients with the FP mutation $(9 / 11(82 \%))$ than in patients who tested negative for the mutation $(21 / 105$ (20\%); $\mathrm{p}=.001)$. Furthermore, among the 30 patients with elevated levels, the GM tryptase level was greater in the FP-positive patients ( $31 \mathrm{vs.} 19 \mathrm{ng} / \mathrm{ml}, \mathrm{p}=0.03$ ). Serum vitamin B12 levels were reported for 120 patients and ranged from 156-10995 pg/ml (GM $632 \mathrm{pg} / \mathrm{ml})$. Elevated serum vitamin B12 levels were also more common in the FP-positive patients (range 401-10,955 pg/ml and present in 13/14 (93\%) vs. FP-negative patients (range 156-2000 pg/ $\mathrm{ml}$ and present in 20/106 (18\%); $\mathrm{p}<0.0001)$. Elevated serum tryptase and/or B12 levels were uncommon in patients with L-HES, occurring in only $3 / 25$ and $1 / 22$ patients tested, respectively,

Serum TARC levels were reported for 82 patients from 4 centers (see methods) and ranged from 22-150100 pg/ml (GM 769 pg/ml). Serum TARC levels were elevated in 75\% (12/16) of patients with L-HES as compared to $36 \%$ (24/66) of patients without a clonal or aberrant T cell population $(\mathrm{p}=.0017)$. Furthermore, GM serum TARC levels in the subset of patients with elevated levels were significantly increased in patients with L-HES as compared to those without (GM 12,979 vs. 3,406 pg/ml, p=0.02). Serum IgE levels were elevated in 83/150 patients tested (55\%). In the 135 patients who were also evaluated for clonal or aberrant $\mathrm{T}$ cell populations, serum IgE was elevated in 19/28 (68\%) patients with L-HES and 56/107 (52\%) in whom a clonal or aberrant population was sought but not found $(\mathrm{p}<0.0001)$. Only one patient in the FP group had an elevated IgE level, and none had elevated serum TARC levels.

Serum IL-5 levels were assessed in 107 patients and ranged from undetectable to $377 \mathrm{pg} / \mathrm{ml}$. IL-5 levels were elevated in 28/107 (26\%) patients: 6 patients with L-HES, 1 patient with the FP mutation, and 21 patients with HES in whom FP mutation analysis and at least one test for $\mathrm{T}$ cell clonality/phenotype had been performed and were negative.

Data pertaining to initial clinical presentation was collected for all patients (Figure 1a and Online Repository Table E1). The most common presenting manifestations of HES were dermatologic $(70 / 188,37 \%)$, followed by pulmonary $(47 / 188,25 \%)$, and gastrointestinal $(25 / 188,14 \%)$. Less than $5 \%(9 / 188)$ of patients had cardiac manifestations at the time of diagnosis. Of note, $6 \%(11 / 188)$ of patients presented with clinically asymptomatic eosinophilia identified on laboratory testing performed for unrelated reasons.

Dermatologic involvement was also the most common subsequent clinical manifestation of HES and was reported in 69\% (130/188) of patients. This was followed in frequency by pulmonary (44\%) and gastrointestinal (38\%) manifestations (Figure 1b). Cardiac disease unrelated to hypertension, atherosclerosis or rheumatic disease was reported in $20 \%(37 / 188)$ 
of the patients. The frequency of cardiac disease was similar in patients with and without the FP mutation (4/18 (22\%) vs. 33/170 (19\%), respectively).

\section{Treatment}

Corticosteroids: Corticosteroids have long been the mainstay of therapy for HES, although the dosing has not been standardized $6,{ }^{9}$. In this series, $179(95 \%)$ patients were treated with corticosteroids, most of whom $(163 / 188 ; 81 \%)$ received corticosteroids as initial therapy. The median maximal daily dose of prednisone (or prednisone equivalent) was $40 \mathrm{mg}$ (range 5-625 $\mathrm{mg}$ ). Most patients $(130 / 179 ; 72 \%)$ were maintained on corticosteroids for some period of time, ranging from 2 months-20 years, with a median maintenance dose of $10 \mathrm{mg}$ daily (range 1-40 $\mathrm{mg} /$ day).

Of 141/188 (75\%) patients who received corticosteroid monotherapy, $120(85 \%)$ experienced a complete or partial response after one month of treatment (Figure 2a). When corticosteroids were used in combination therapy (most often due to failure or corticosteroid toxicity), the most frequent second agents added were hydroxyurea (36 patients) and interferon alpha (IFN, 24 patients). Responses (complete or partial) were achieved in 69\% (25/36) of patients receiving hydroxyurea and corticosteroids and 75\% (18/24) of patients treated with IFN and corticosteroids.

Prednisone was discontinued in $42 \%$ (75/179) of patients. The most frequently cited reasons for discontinuation were lack of efficacy (40\%) and "other" (40\%) (Figure 2b). The most common reasons for the response "other" were efficacy of another drug, most frequently imatinib or anti-IL-5 antibody $(\mathrm{n}=12)$, and disease remission $(\mathrm{n}=12)$.

Elevated serum IgE and TARC levels have been associated with corticosteroid responsiveness in patients with HES 10, 11. Serum IgE levels were elevated in 77/142 (54\%) patients who received corticosteroid therapy and for whom serum IgE levels were available. The percentage of patients with elevated $\mathrm{IgE}$ was comparable in patients who responded to steroids and those who did not (73/129 (57\%) vs. 4/13 (31\%); p=0.09, Fisher's exact test). Similarly, GM serum IgE levels were similar in patients with a complete $(125 \mathrm{IU} / \mathrm{ml})$, partial $(222 \mathrm{IU} / \mathrm{ml})$ or lack of response $(70 \mathrm{IU} / \mathrm{ml})$ to corticosteroid therapy (Figure 3a).

Serum TARC levels were elevated in 41/82 (50\%) patients who received corticosteroid therapy and for whom levels were available. Not only were GM TARC levels significantly elevated in patients who responded to corticosteroids as compared to non-responders ( 979 vs. $242 ; \mathrm{p}=.01$ ), but serum TARC levels $>10,000 \mathrm{pg} / \mathrm{ml}(\mathrm{n}=11)$ were reported only among prednisone responders (Figure $3 b$ ).

Hydroxyurea: Thirty-four percent (64/188) of patients were treated with the oral cytotoxic agent hydroxyurea, with a median maximum daily dose of $1000 \mathrm{mg}$ (range 500-2000 mg).

Eighteen patients received hydroxyurea as monotherapy, of whom $6(33 \%)$ achieved a complete response and 7 (39\%) a partial response (Figure 2a). Hydroxyurea was discontinued in the majority of patients $(49 / 64 ; 77 \%)$, primarily due to lack of efficacy $(23 / 49 ; 47 \%)$ and medication intolerance secondary to treatment-related side effects $(21 / 49 ; 43 \%)$ (Figure 2b).

Interferon alpha (IFN): Approximately one quarter of the patients (46/188) were treated with IFN, with a median maximal dose of 14 million units per week (range 3-40 million units per week). Only 12 patients received IFN as monotherapy, of whom 2 (17\%) achieved a complete response and $4(33 \%)$ a partial response at 1 month (Figure 2a). IFN was discontinued in all but 6 patients $(87 \%)$. The most common reasons for drug discontinuation were medication intolerance $(20 / 40 ; 50 \%)$, lack of efficacy $(14 / 40 ; 36 \%)$ and cost $(1 / 40 ; 3 \%)$ (Figure 2b). 
Cyclosporine: 11/188 (6\%) patients were treated with cyclosporine (median maximal daily dose of $200 \mathrm{mg}$; range $150-500 \mathrm{mg}$ ). Of the 5 patients who received cyclosporine monotherapy, one patient achieved a complete response (20\%), and 2 patients (40\%) achieved partial responses (Figure 2a). The medication was discontinued in $9 / 11$ patients (82\%), including the patient who responded completely for reasons of medication intolerance (Figure 2b).

Imatinib: The tyrosine-kinase inhibitor, imatinib, was initiated in 68/188 patients (36\%), of whom 17 were known to be positive for the FP mutation. The median maximal dose used was $400 \mathrm{mg}$ daily (range $100 \mathrm{mg}$ twice weekly to $600 \mathrm{mg}$ daily). Of the 31 patients who received imatinib monotherapy, 20/31 (65\%) achieved a complete response and 2/31 (6\%) a partial response (Figure 2a). Of the FP-positive patients, 15/17 (88\%) responded completely and two (12\%) had no response 12,13 . In contrast, only 10/43 (23\%) FP-negative patients who received imatinib experienced a complete $(n=6)$ or partial $(n=4)$ response $(\mathrm{p}<.0001$ compared to the FPpositive patients).

Imatinib was discontinued in $41 / 68$ patients, mostly due to lack of efficacy $(33 / 41 ; 80 \%)$ (Figure $2 \mathrm{~b}$ ). The remaining $8 / 41$ patients discontinued imatinib therapy because of medication intolerance ( 4 patients), unspecified reasons ( 2 patients), the initiation of an anti-IL-5 clinical trial (1 patient), or the desire to have children (1 patient).

Anti-IL-5 antibody: A total of 62/188 (33\%) patients received at least one dose of anti-IL-5 monoclonal antibody therapy with mepolizumab (GlaxoSmithKline; $750 \mathrm{mg} / \mathrm{month} ; \mathrm{n}=59$ ) or reslizumab (Ception; $1-3 \mathrm{mg} / \mathrm{kg} / \mathrm{month} ; \mathrm{n}=2)$, or both $(\mathrm{n}=1)$. Of the 15 patients who received mepolizumab monotherapy, 12/15 (80\%) achieved a complete response one month after the initiation of therapy (Figure 2a). As has been previously reported ${ }^{17}$, two patients received reslizumab monotherapy, both of whom responded after 1 month of therapy. The remaining 45 patients were treated concomitantly with mepolizumab and corticosteroids. Thirty-four of $45(76 \%)$ responded completely after 1 month of mepolizumab and an additional $5(11 \%)$ had a partial response.

Although anti-IL-5 therapy was discontinued in 29/62 (47\%) patients the most frequent cause for discontinuation (18 patients; 62\%) was the completion of a clinical trial (listed as "other") (Figure 2b). An additional 10 patients (34\%) discontinued due to lack of efficacy. Only 1 patient discontinued anti-IL-5 treatment due to medication intolerance.

Other agents: Several other medications were used for treatment of HES (see Table E2 in the Online Repository); however too few patients were treated to draw conclusions for individual agents.

\section{Discussion}

One of the major problems with previously reported series of HES patients has been referral bias, with single centers more likely to see patients with end organ manifestations that fall within the area of expertise of a particular subspecialty interested in HES. This has been compounded by the tendency to publish cases of the most severely affected patients, a disproportionate number of whom, in retrospect, were likely FP-positive. Patients in the current series were referred to groups with international recognition in the diagnosis and treatment of HES, composed of a wide variety of subspecialty physicians. Consequently, the data compiled are more likely to represent the true spectrum of HES. The major limitation of this study was the retrospective design and resultant lack of standardization of laboratory studies between the different sites. Despite these limitations, however, a number of interesting conclusions can be drawn. 
In contrast to the marked (9:1) male predominance of HES reported in the literature, the ratio of males to females in the current study was 11:8. This likely reflects the fact that FP-positive patients, who are almost exclusively male, were overrepresented in previous series and confirms data from recent studies in which FP-positive patients were excluded7. Similarly, early assessments of the relative prevalence of end organ manifestations were gleaned from case reports and small series and tended to overestimate more serious consequences of HES, including cardiac and neurologic involvement 2 . In the current series, the most common presenting manifestations of HES were dermatologic, pulmonary and gastrointestinal. Cardiac and neurologic complications did occur, but were relatively uncommon at the initial presentation. Earlier diagnosis and the availability of better therapies likely contributed to the improved HES patient outcomes in the current series. It is important to note that 11 of the 188 patients presented with asymptomatic eosinophilia found on routine lab testing. Of these, two were found to have FP-mutation positive CEL, a condition associated with high morbidity and mortality (up to $50 \%$ at 5 years) in the absence of imatinib therapy 5 . These findings highlight the importance of a comprehensive evaluation and close follow-up of patients presenting with unexplained hypereosinophilia.

There has been considerable controversy regarding the prevalence of L-HES and the FPmutation among patients meeting criteria for HES. Early studies likely overestimated the prevalence of these two entities due to selection bias ${ }^{3,4}$. More recently, the prevalence of the FP mutation has been estimated at $14 \%$ in a retrospective analysis of 81 patients with primary eosinophilia $\geq 1.5 \times 10^{9} / \mathrm{L}$ who underwent bone marrow examination ${ }^{14}$. The prevalence of FPpositive patients was slightly lower in our study (10\%), possibly due to the inclusion of patients in whom a bone marrow examination was not deemed necessary (i.e. less likely to have myeloproliferative disease). The association between elevated serum vitamin B12 and tryptase levels and the presence of the FP mutation was confirmed in the present study. Of note, extremely high levels of serum vitamin B12 (>2000 pg/ml) were observed only in the FPpositive group, suggesting that this may be a more discriminating biomarker of myeloproliferative HES.

Confirmation of L-HES is complex, ideally involving both lymphocyte phenotyping and TCR analysis. Consequently, differences in technique as well as the characteristics of the population studied likely account for the variability in the reported prevalence of L-HES, ranging from $14-31 \% 3,15,16$. In the present study, $17 \%$ of patients who were tested had clonal/abnormal populations of T cells detected by PCR or flow cytometry. Although it is debatable whether L-HES can be diagnosed on the basis of a clonal population identified by PCR in the absence of a detectable aberrant phenotype by flow cytometry ( $8.3 \%$ of the patients in the current study), the fact that some patients with clonal TCR rearrangement patterns have strikingly elevated serum TARC and/or IgE levels ${ }^{11}$ suggests that aberrant $\mathrm{T}$ cell populations not identified using current antibody panels may be responsible for the eosinophilia in these patients. Nevertheless, a prospective trial using standardized techniques is clearly necessary to obtain an accurate assessment of the prevalence of the lymphocytic variant of HES.

Early efficacy studies and extensive clinical experience have proven corticosteroids to be the first line agent for the treatment of FP-negative HES 6. Although the previously reported association between prednisone responsiveness and elevated serum IgE levels ${ }^{10}$ was not confirmed in this study, TARC levels were significantly higher in patients who responded to prednisone. There was no difference between the serum IL-5 levels in patients who responded to prednisone compared to those who failed to respond (data not shown). Most patients were maintained on low to moderate dose prednisone therapy (5-20 mg daily). Although this would seem to indicate that the need for alternative therapies is small, the study questionnaire was not designed to detect steroid toxicities that did not lead to drug discontinuation. Furthermore, the majority of corticosteroid-responsive patients went on to receive a second-line agent, 
consistent with a higher rate of steroid toxicity and/or resistance than is evident from the collected data.

In the past 5-10 years, HES subtypes have been defined and a number of new, targeted agents have been developed, including imatinib mesylate and humanized monoclonal antibodies to IL-5. The restriction of this retrospective study to patients seen after 2001 was intended to maximize inclusion of data on these newer agents. As expected, imatinib was extremely effective in FP-positive patients with resistance described in only 2 patients. The $23 \%$ response rate in FP-negative patients is more difficult to interpret as the database did not include sufficient information to distinguish patients with myeloproliferative features who may be more likely to respond to imatinib. Although anti-IL-5 therapy was well-tolerated with an overall response rate of $80 \%$, all patients received this agent in clinical trials, the majority of which required patients to be steroid-responsive ${ }^{7,13}$, or were limited to a small number of doses ${ }^{17}$. Consequently, conclusions regarding the long-term efficacy of anti-IL-5 therapy and the most appropriate patients for treatment await further study.

In summary, HES is a rare group of disorders for which unbiased information on demographics, clinical manifestations and treatment responses is scarce. Although the current study has limitations due to its retrospective design, it represents the largest multicenter study of unselected patients with HES to date. As such, it not only provides useful information for clinicians involved in the care of HES patients, but will hopefully stimulate carefully designed prospective trials for the treatment of this disorder.

\section{Key Messages}

- Classically defined hypereosinophilic syndrome is a heterogeneous group of varied disorders, the majority of which remain idiopathic.

- Corticosteroids are extremely effective in the treatment of FIP1L1/PDGFRAnegative HES, but their use may be limited by side effects.

- Carefully designed prospective trials are required to advance the diagnosis and treatment of HES.

\section{Supplementary Material}

Refer to Web version on PubMed Central for supplementary material.

\section{Acknowledgments}

The authors would like to thank Dr. Amal Assa'ad, Bridget Buckmeier, Cheryl Talar-Williams, Melissa Law and Marilyn Hartsell for their participation in the clinical care of the patients.

Funding/Support: This study was supported by the Division of Intramural Research of the NIAID/NIH (Drs. Klion, Ogbogu and Nutman), grants AI41472 and AI72265 from the NIH (Dr. Bochner), grant AI061097 from the NIH (Dr. Gleich), the Human Immunology grant program of the Dana Foundation (Dr. Bochner), the Swiss National Science Foundation (Drs. Simon), the Belgian National Fund for Scientific Research (Dr. Roufosse) and the Campaign Urging Research for Eosinophilic Disorders (Dr. Rothenberg). Dr. Bochner is a Cosner Scholar in Translational Research from Johns Hopkins University. The funding organizations had no role in the design and conduct of the study; collection, management, analysis, and interpretation of the data; and preparation, or review of the manuscript. The manuscript was approved by the Division of Intramural Research, NIAID/NIH.

\section{Abbreviations}

$\begin{array}{ll}\text { FIP1L1 } & \text { Fip1-like } 1 \\ \text { FP } & \text { FIP1L1-PDGFRA }\end{array}$




$\begin{array}{ll}\text { HES } & \text { Hypereosinophilic syndrome } \\ \text { L-HES } & \text { Lymphocytic variant hypereosinophilic syndrome } \\ \text { M-HES } & \text { Myeloproliferative variant hypereosinophilic syndrome } \\ \text { PDGFRA } & \text { Platelet derived growth factor receptor alpha } \\ \text { CEL } & \text { Chronic eosinophilic leukemia } \\ \text { TARC } & \text { Thymus and activation-related chemokine } \\ \text { GM } & \text { Geometric mean }\end{array}$

\section{References}

1. Chusid MJ, Dale DC, West BC, Wolff SM. The hypereosinophilic syndrome: analysis of fourteen cases with review of the literature. Medicine (Baltimore) 1975;54:1-27. [PubMed: 1090795]

2. Weller PF, Bubley GJ. The idiopathic hypereosinophilic syndrome. Blood 1994;83:2759-2779. [PubMed: 8180373]

3. Simon HU, Plotz SG, Dummer R, Blaser K. Abnormal clones of T cells producing interleukin-5 in idiopathic eosinophilia. N Engl J Med 1999;341:1112-1120. [PubMed: 10511609]

4. Cools J, DeAngelo DJ, Gotlib J, Stover EH, Legare RD, Cortes J, et al. A novel tyrosine kinase created by the fusion of the PDGFRA and FIPIL1 genes is a therapeutic target of imatinib in idiopathic hypereosinophilic syndrome. N Engl J Med 2003;348:1201-1214. [PubMed: 12660384]

5. Klion AD, Noel P, Akin C, Law MA, Gilliland DG, Cools J, et al. Elevated serum tryptase levels identify a subset of patients with a myeloproliferative variant of idiopathic hypereosinophilic syndrome associated with tissue fibrosis, poor prognosis and imatinib-responsiveness. Blood 2003;101:46604666. [PubMed: 12676775]

6. Klion AD, Bochner BS, Gleich GJ, Nutman TB, Rothenberg ME, Simon HU, et al. Approaches to the treatment of hypereosinophilic syndromes: a workshop summary report. J Allergy Clin Immunol 2006;117:1292-1302. [PubMed: 16750989]

7. Rothenberg ME, Klion AD, Roufosse FE, Kahn JE, Weller PF, Simon HU, et al. Treatment of patients with the hypereosinophilc syndrome with mepolizumab. N Engl J Med 2008;358:1215-1228. [PubMed: 18344568]

8. Roufosse F, Cogan E, Goldman M. Lymphocytic variant hypereosinophilic syndromes. Immunol Allergy Clin N Am 2007;27:389-413.

9. Simon HU, Cools J. Novel approaches to therapy of hypereosinophilic syndromes. Immunol Allergy Clin North Am 2007;27:519-527. [PubMed: 17868862]

10. Bush RK, Geller M, Busse WW, Flaherty DK, Dickie HA. Response to corticosteroids in the hypereosinophilic syndrome. Association with increased serum IgE levels. Arch Intern Med 1978;138:1244-1246. [PubMed: 677979]

11. de Lavareille A, Roufosse F, Schmid-Grendelmeier P, Roumier AS, Schandene L, Cogan E, et al. High serum thymus and activation-regulated chemokine levels in the lymphocytic variant of the hypereosinophilic syndrome. J Allergy Clin Immunol 2002;110:476-479. [PubMed: 12209097]

12. Simon D, Salemi S, You sefi S, Simon HU. Primary resistance to imatinib in Fip1-like 1-plateletderived growth factor receptor alpha-positive eosinophilic leukemia. J Allergy Clin Immunol 2008;121:1054-1056. [PubMed: 18234315]

13. Stein ML, Villanueva JM, Buckmeier BK, Yamada Y, Filipovich AH, Assa'ad AH, et al. Anti-IL-5 (mepolizumab) therapy reduces eosinophil activation ex vivo and increases IL-5 and IL-5 receptor levels. J Allergy Clin Immunol 2008;121:1473-1483. [PubMed: 18410960]

14. Pardanani A, Brockman SR, Paternoster SF, Flynn HC, Ketterling RP, Lasho TL, et al. FIP1L1/ PDGFRA fusion: prevalence and clinicopathologic correlates in 89 patients with moderate to severe eosinophilia. Blood 2004;104:3038-3045. [PubMed: 15284118] 
15. Vaklavas C, Tefferi A, Butterfield J, Ketterling RP, Vertovsek S, Kantarjian H, et al. 'Idiopathic' eosinophilia with an Occult T-cell clone: prevalence and clinical course. Leuk Res 2007;31:691694. [PubMed: 17095087]

16. Roche-Lestienne C, Lepers S, Soenen-Cornu V, Kahn JE, Lai JL, Hachulla E, et al. Molecular characterization of the idiopathic hypereosinophilic syndrome (HES) in 35 French patients with normal conventional cytogenetics. Leukemia 2005;19:792-798. [PubMed: 15772698]

17. Klion AD, Law MA, Noel P, Haverty TP, Nutman TB. Safety and efficacy of the monoclonal antiinterleukin 5 antibody, SCH55700, in the treatment of patients with the hypereosinophilic syndrome. Blood. 2004 

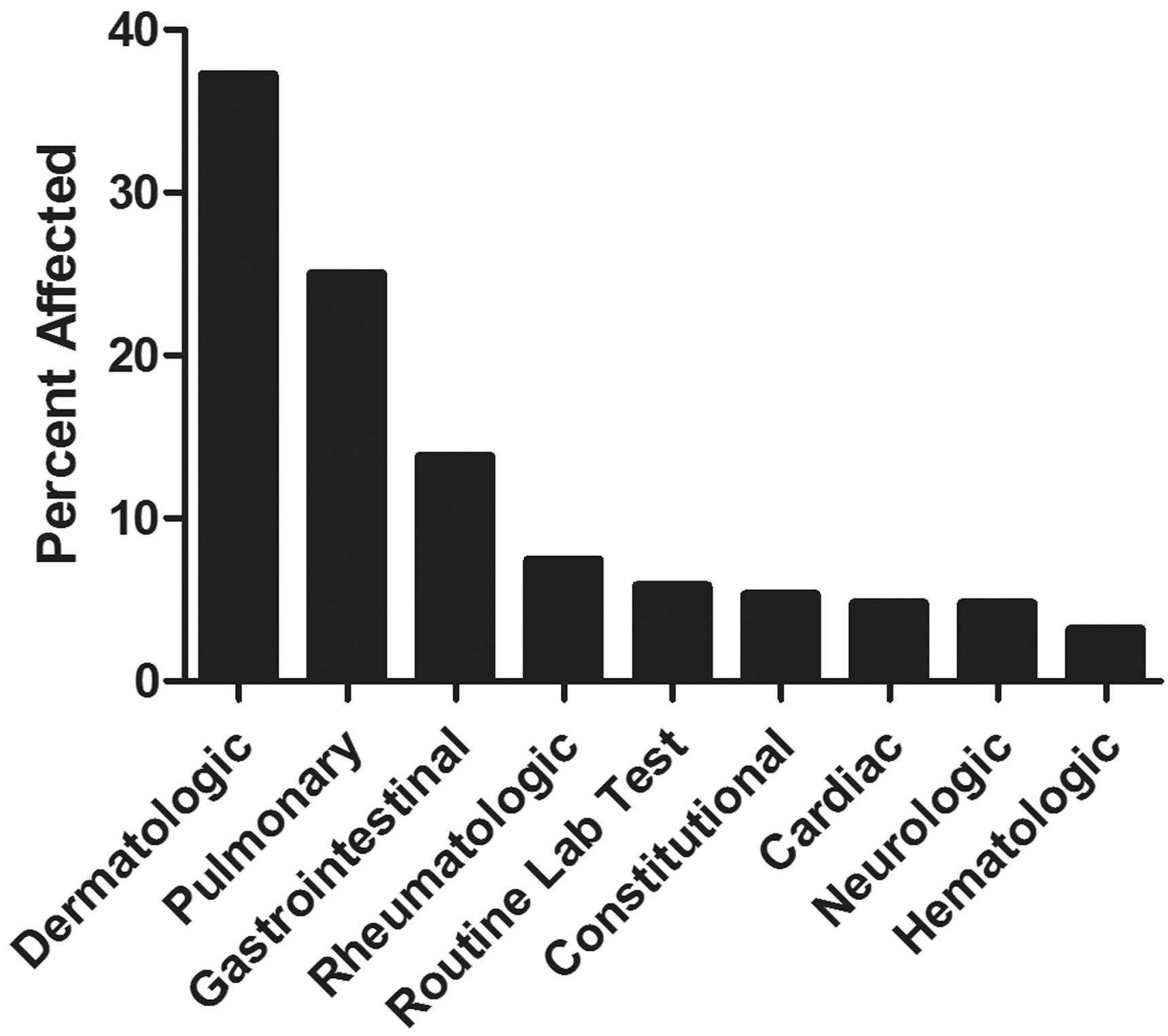

\section{Initial Clinical Presentation}




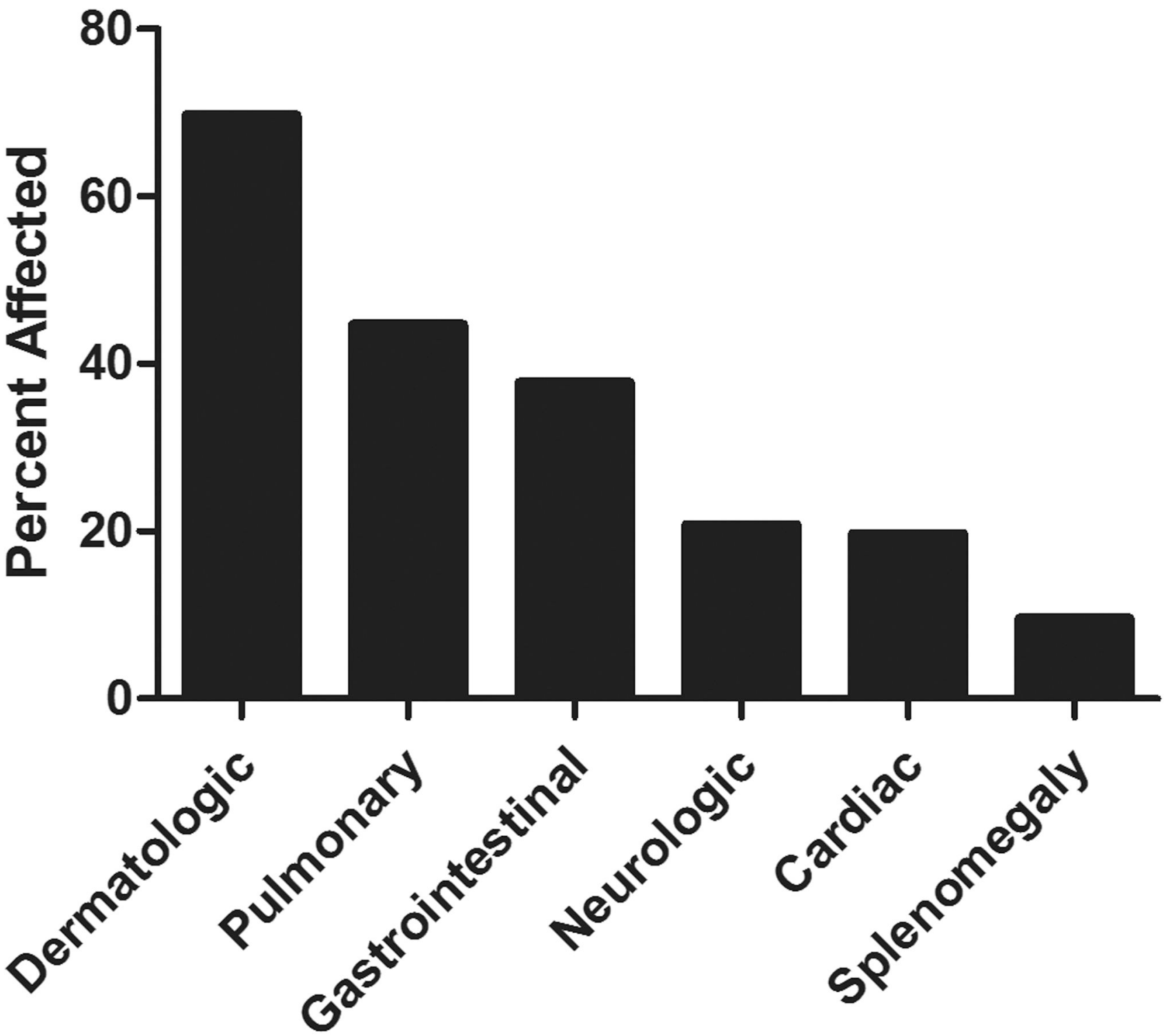

\section{Subsequent Clinical Manifestation}

Figure 1.

Clinical manifestations of HES. The clinical manifestations at initial presentation (A) and at the time of the retrospective analysis (B) are shown as the percent of patients with evidence of organ involvement referable to a given category. Reported manifestations in each of the categories are listed in Table E1 of the Online Repository. 
Drug Response at 1 Month

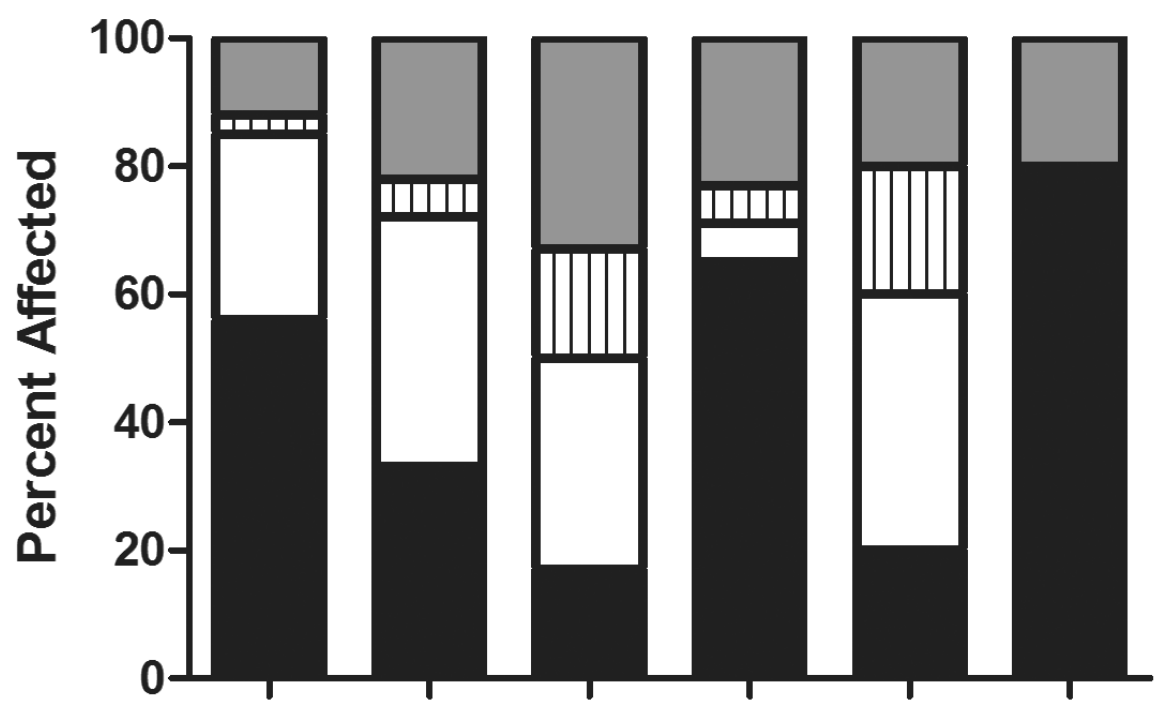

Complete

$\square$ Partial

III Unknown

$\square$ None

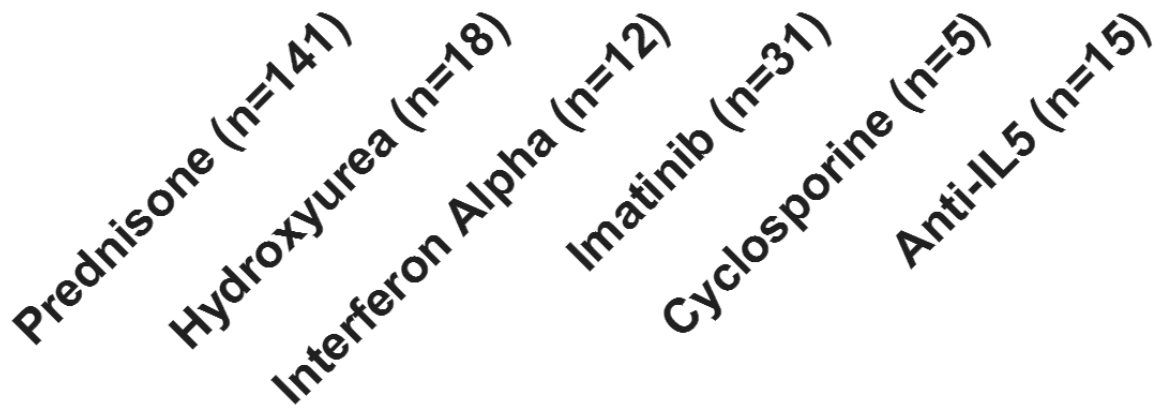

Treatment 


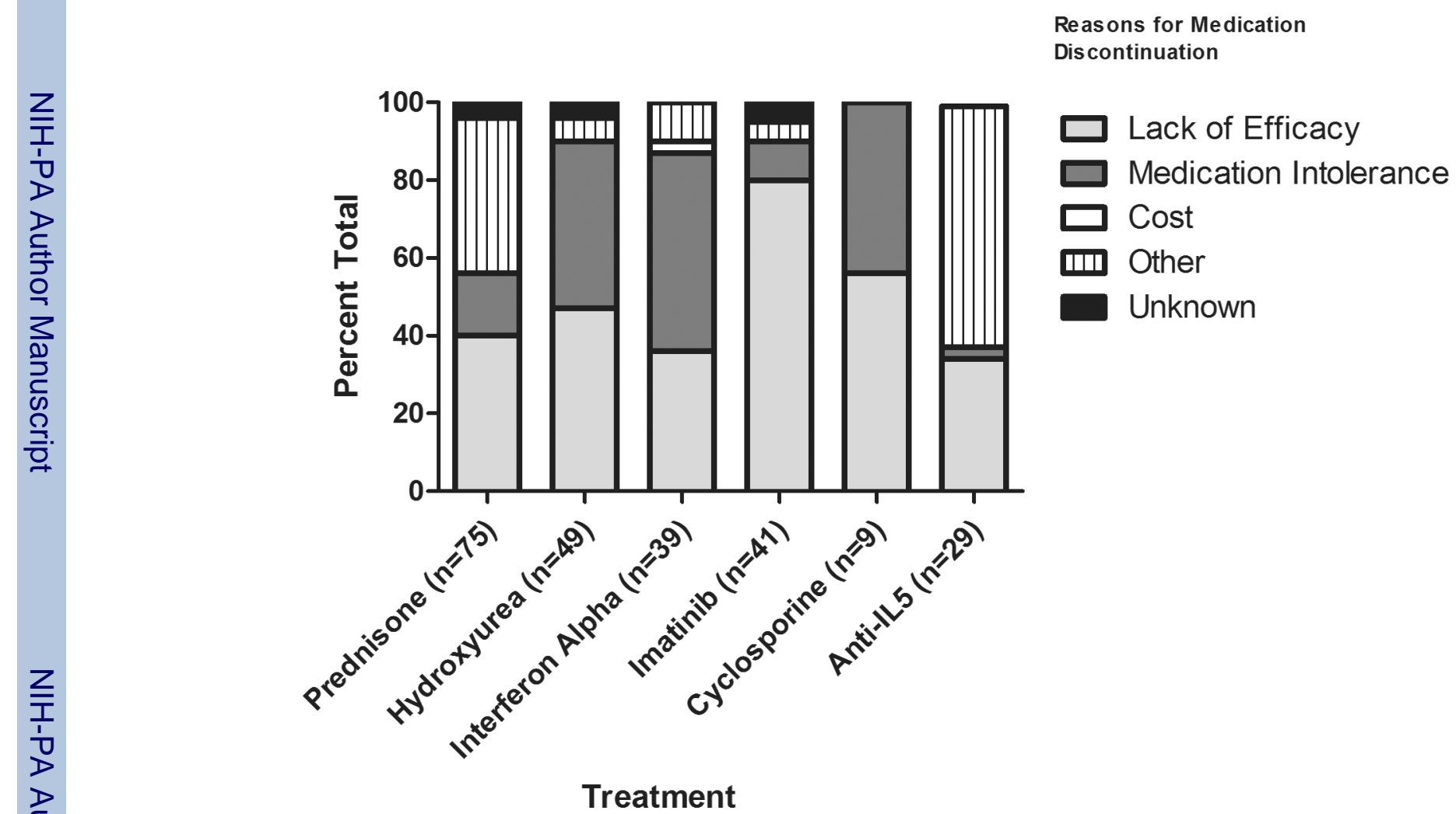

Figure 2.

Response to Treatment. The bars represent response rates after one month of therapy (A) and reasons for drug discontinuation (B). Responses were defined as complete (normalization of absolute eosinophil count (AEC) and clinical symptom improvement), partial (reduction of AEC, but not to normal levels, and/or improvement in symptoms) or no response (neither reduction of AEC nor improvement in symptoms). 


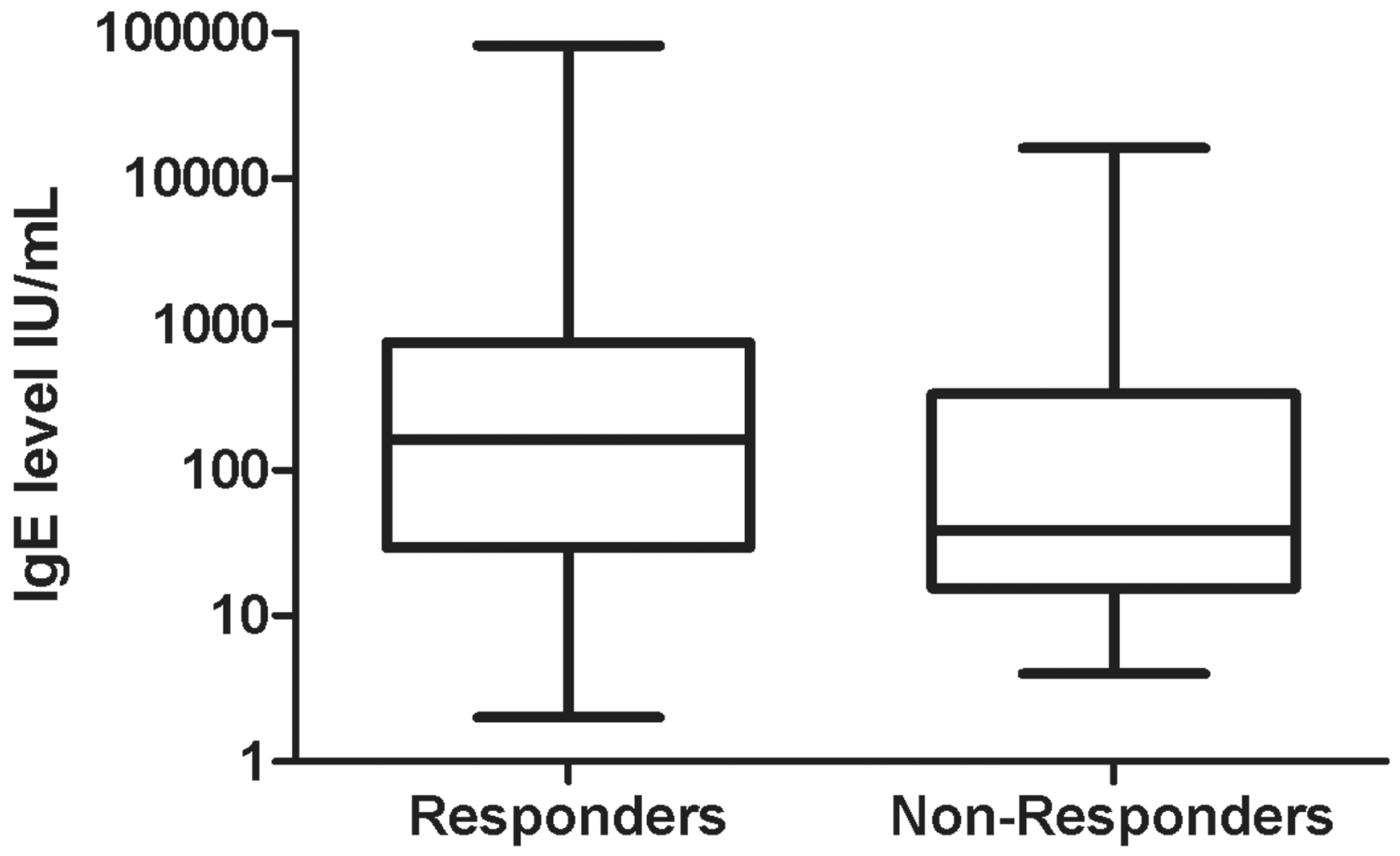




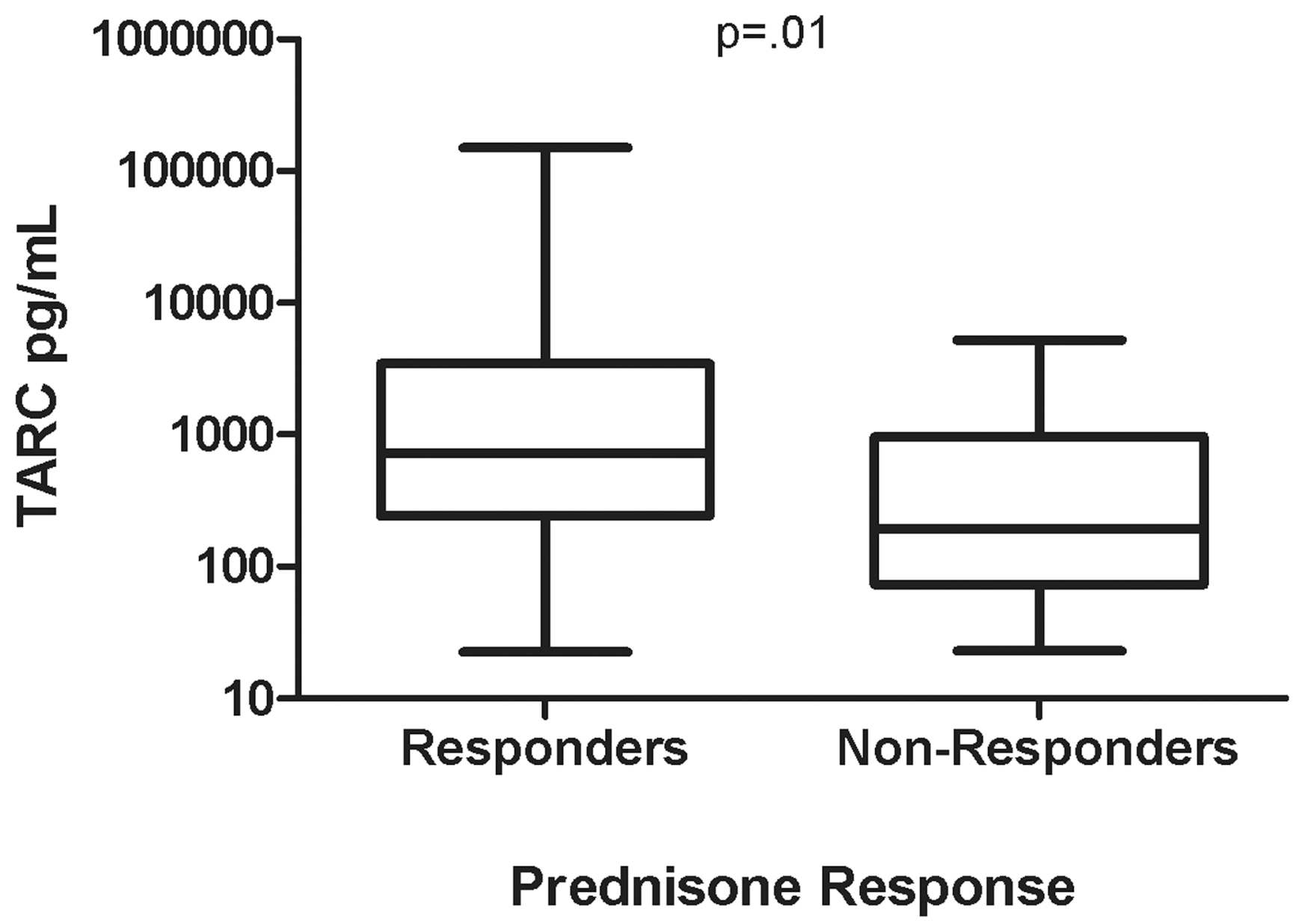

Figure 3.

Association of serum TARC, but not serum IgE levels with prednisone responsiveness. Serum $\operatorname{IgE}(\mathrm{A})$ and TARC (B) levels for prednisone responders ( $\mathrm{n}=129$ and 75, respectively) and nonresponders ( $\mathrm{n}=13$ and 8 , respectively) are shown using box and whiskers plots. The whiskers represent the minimum and maximum values and the horizontal lines represent the lower quartile, median, and upper quartile. 
Table 1

Baseline characteristics of patients

\begin{tabular}{|c|c|c|c|c|}
\hline Center* & $\begin{array}{c}\text { Number } \\
\text { of patients }\end{array}$ & $\begin{array}{c}\text { Gender } \\
\text { (male/female) }\end{array}$ & $\begin{array}{c}\text { Median age at } \\
\text { diagnosis } \\
\text { (range) }\end{array}$ & $\begin{array}{c}\text { GM peak } \\
\text { eosinophil count } \\
\times 10^{9} / \mathrm{L} \\
(\text { range })\end{array}$ \\
\hline BRU & 22 & $12 / 10$ & $\begin{array}{c}48 \\
(15-81)\end{array}$ & $\begin{array}{c}6.29 \\
(2.0-16.7)\end{array}$ \\
\hline MUN & 8 & $5 / 3$ & $\begin{array}{c}43 \\
(12-65)\end{array}$ & $\begin{array}{c}3.37 \\
(1.5-8.32)\end{array}$ \\
\hline LEIC & 14 & $10 / 4$ & $\begin{array}{c}62 \\
(30-78)\end{array}$ & $\begin{array}{c}10.52 \\
(2.12-80.90)\end{array}$ \\
\hline BALT & 15 & $8 / 7$ & $\begin{array}{c}46 \\
(23-85)\end{array}$ & $\begin{array}{c}5.86 \\
(2.0-59.75)\end{array}$ \\
\hline CIN & 21 & $10 / 11$ & $\begin{array}{c}37 \\
(15-56)\end{array}$ & $\begin{array}{c}5.45 \\
(1.5-42.0)\end{array}$ \\
\hline MINN & 16 & $7 / 9$ & $\begin{array}{c}54 \\
(9-69)\end{array}$ & $\begin{array}{c}5.91 \\
(1.89-29.02)\end{array}$ \\
\hline BOS & 7 & $4 / 3$ & $\begin{array}{c}45 \\
(23-59)\end{array}$ & $\begin{array}{c}7.30 \\
(3.5-14.39)\end{array}$ \\
\hline SLC & 13 & $8 / 5$ & $\begin{array}{c}30 \\
(6-74)\end{array}$ & $\begin{array}{c}11.34 \\
(2.4-85.0)\end{array}$ \\
\hline BETH & 39 & $12 / 14$ & $\begin{array}{c}42 \\
(16-69)\end{array}$ & $\begin{array}{c}8.98 \\
(2.2-400)\end{array}$ \\
\hline BER & 14 & $6 / 8$ & $\begin{array}{c}54 \\
(8-69)\end{array}$ & $\begin{array}{c}5.18 \\
(1.5-340)\end{array}$ \\
\hline SUR & 19 & $9 / 10$ & $\begin{array}{c}43 \\
(14-65)\end{array}$ & $\begin{array}{c}5.61 \\
(1.7-31.60)\end{array}$ \\
\hline Total & 188 & $105 / 82$ & $\begin{array}{c}45 \\
(6-85)\end{array}$ & $\begin{array}{c}6.602 \\
(1.5-400)\end{array}$ \\
\hline
\end{tabular}

Gender distribution, median age at diagnosis, and geometric mean peak eosinophil count are provided for each of the participating centers: BRU=Erasme Hospital, Brussels, Belgium; MUN=Technical University of Munich, Munich, Germany; LEIC=University of Leicester, Leicester, UK ; BALT=Johns Hopkins Hospital, Baltimore, USA; CIN= Cincinnati Children's Hospital Medical Center, Cincinnati, USA; MINN= Mayo Clinic, Rochester, USA; BOS=Harvard Medical School, Boston, USA; SLC= University of Utah, Salt Lake City, USA; BETH= Laboratory of Parasitic Diseases, National Institutes of Health, Bethesda, USA; BER=University of Bern, Bern, Switzerland; SUR=Hopital Foch, Suresnes, France 